\title{
Effects of Water Level and Nutrients on Growth and Chemical Composition of Two Wetland Sedges in the Nile Delta
}

\author{
A.A. Khedr ${ }^{*}$, M.S.Serag, S. Rabei, A. Doma \\ Botany Department, Faculty of Science, Damietta University, Egypt
}

Received: 25 June 2013 / Accepted: 19 August 2013

*Corresponding author (Tel: +20. 01220520698, email: abdelkhedr@yahoo.com)

\begin{abstract}
Two wetland species namely Cyperus laevigatus L. and Cyperus articulatus L. were grown under different water levels and nutrient concentrations. For $C$. laevigatus, the highest value of plant height, biomass and survival were recorded when water level was at soil surface, while in $C$. articulatus grown under high nutrient treatment the total biomass was increased by the decrease of water level. Results showed a highly significant effect of water level on C. laevigatus density and biomass. Nutrient addition affected biomass and plant density, but interaction between Nutrient addition and water level affects plant height significantly. In case of C. articulatus Nutrient addition and water level showed significant variation on biomass and plant height. The highest $\mathrm{Na}^{+}, \mathrm{K}^{+}$, total-P and total-N contents in the above-grounds parts of both species were detected in plant grown under high nutrient medium and water level below soil surface. The obtained results will be useful for the optimal management of sedge plants in relation to water and soil of the Nile Delta wetlands.
\end{abstract}

Keywords: Chemical composition, growth, Nile Delta, sedges, survival, wetlands

\section{Introduction}

The productive lands are diminishing worldwide at a very high rate. The main cause of this catastrophe is the occurrence of desertification and the increase of soil salinity. Egypt, like other developing countries of the arid and semi-arid regions, faces four major problems, namely: 1) high rate of population increase, 2) limited quality of water, 3) existence of salt affected lands, 4) shortage of food and feed. Therefore, studies should be directed towards solving these problems and in particular to the rehabilitation of salt affected lands. Salt-tolerant plants may provide a logical option for many developing countries. These plants can be grown using land and water unsuitable for conventional crops and can provide food, fuel, fodder, fibers, resins, essential oils and summer green fodder [1-5]. Wetland plants have been screened for their productivity and/or nutritional potential [3]. Some halophytic species have been demonstrated as forage plants [6].

Sedges (Cyperaceae) are important components of the vascular flora of the wetlands and coastal habitats $[7,8]$, yet only limited work has been done to evaluate the forage potential of sedges. Cyperus laevigatus and C. articulatus had been found with a direct agronomic use as a fodder crops [9]. In the Nile Delta, these species frequently occur in marshy, saline habitats. They predominate in badly drained and heavily textured saline soils $[10,11]$.

Using C. laevigatus and C. articulatus in the 
Egyptian saline agriculture as summer forage in arid lands seems to be important especially where the relatively salt-sensitive crops cannot grow. These species could be established in saline or sodic and waterlogged soils of the Nile delta in particular in wet saline habitats of the northern lakes of Mediterranean coastal areas where the water sources for irrigation are limited. In addition to the high reclamation potential of these plants, they are considered as a good forage especially in summer and can be irrigated with diluted seawater [3].

The main objective of this study is to evaluate the biomass allocation and chemical composition of the two sedges namely: $C$. laevigatus and $C$. articulatus. This can be assessed by comparing growth performance in controlled growth conditions, affect biomass responses of either species.

\section{Materials and methods}

\section{Study area}

The genus Cyperus is the most important and largest genus of family Cyperaceae in Egypt. It is distributed in tropical, subtropical and temperate zone. It is commonly met with in marshy places, those temporarily flooded with water, maritime or desert sand dunes where it acts as sandbinders or as weeds in fields (common in fields of rice, clover and maize). Nineteen species (including only one in cultivation) grow in Egypt [15].

Two sedges $C$. laevigatus and $C$. articulatus form an extremely important component of wetlands, river banks, and estuaries (Damietta and Rosetta) of the coastal area of the Nile Delta. $C$. leavigatus and $C$. articulatus are palatable sedges for livestock. They are growing in River Nile banks. The former is more widespread extending its growth from Damietta to Aswan, while the latter is abundant the northern section of Damietta estuary.

\section{Experimental Design}

Cyperus articulatus and C. laevigatus rhizomes were collected from the wetlands of the Nile Delta. The rhizomes are cut to equal parts, each with active bud transplantation in the green house under natural conditions. One-week old buds were transplanted in sterile washed sand in cement tanks ( $30 \mathrm{~cm}$ deep, $25 \mathrm{~cm}$ width, $50 \mathrm{~cm}$ in length).

Two tanks randomly assigned containing only C. articulatus plants and two tanks containing $C$. laevigatus plants, for each treatment.

We assigned water and nutrient levels in a $4 \mathrm{x}$ 2 randomized block design (8 containers) and replicated these three times for a total of a 24 containers. The hydric treatment consisted of three water levels: 1- moist soil where level were of $5 \mathrm{~cm}$ below soil surface, 2- saturated soil with water level even with soil, and 3- submersedwater level $5 \mathrm{~cm}$ above soil surface.

Each water regime was treated with two nutrient levels. NPK fertilizer $(1: 2: 1)$ was added with low concentration $(0.04 \mathrm{~g} /$ /iter of water) and high concentration ( $0.2 \mathrm{~g} /$ liter of water). The application of nutrient addition was one month after transplantation and repeated twice a month.

\section{Chemical analysis of the two sedges}

$\mathrm{Na}^{+}$and $\mathrm{K}^{+}$were determined in the previously prepared digest using a Flame Photometer type M7D according to Allen et al. [12]. Total phosphorus was determined according to the method of John [13] with some modifications. Total-N was estimated by the semi-automatic Kjeldahl Model Pro Nitro, for distillation and absorbance was measured using Spectrophotometer [14].

\section{Statistical Analysis}

Five replicates of each planting regime (water level X nutrient level) in each container were used for statistical analysis of study plants.

Effect of water and nutrient levels and their interactions on density, height and biomass were compared for each species by analysis of variance (two-way ANOVA) according to Kleinbaum et al. [16].

\section{Results}

Effect of water level and nutrients on survival, plant height, density, biomass

It seems that the survival of both species is high in the tank with water level with soil surface at high nutrient level. In low nutrient treatment, the survival was increased with the decreasing of water level for both species. The highest values of survival and plant height of $C$. articulatus were recorded at water level with soil surface 
(100\% and $44 \mathrm{~cm}$ respectively). In high nutrient treatment, the total biomass was increased by the decreasing of water level (Table 1). The highest values of total biomass and plant height $(C$. articulatus) were recorded at water level below soil surface $3.49 \mathrm{gm}$ and $45.37 \mathrm{~cm}$ respectively.

Analysis of variance of the effect of nutrient and water levels on plant height of $C$. laevigatus and $C$. articulatus is presented in Table 2. There was significant effect of water depth on $C$. laevigatus height $(\mathrm{p}<0.001)$ compared with $C$. articulatus $(\mathrm{p}<0.05)$. The interaction between water depth and nutrient level showed highly significant effect on the height of $C$. laevigatus $(\mathrm{p}<0.001)$. The results showed significant effect between plant density with nutrient level on $(\mathrm{p}<0.01)$ and water depth $(\mathrm{p}<0.001)$ of $C$. laevigatus. The interaction between water depth and nutrient level showed no significant effect on the density of $C$. laevigatus. The results showed highly significant effect of nutrient level and water depth $(\mathrm{p}<0.001)$ on biomass of $C$. laevigatus compared with $C$. articulatus $(\mathrm{p}<0.01)$. The interaction between water depth and nutrient level showed no significant effect on biomass of both $C$. laevigatus and $C$. articulatus.

\section{Effect of water level and nutrients on chemical composition of $C$. laevigatus}

The concentration of $\mathrm{K}^{+}$and $\mathrm{Na}^{+}$in above-ground and below-ground parts of $\mathrm{C}$. laevigatus were increased by decreasing water level in high nutrient treatment (Fig. 1). The highest values of total $\mathrm{P}$ were recorded at water level with soil surface in both below-ground and above-ground parts $(0.072$ and $0.073 \mathrm{mg} / 100 \mathrm{gm})$ respectively. Total-N concentration was decreased by increasing of water level in above-ground parts in low nutrient medium, but in below-ground parts the highest value of total- $\mathrm{N} 0.12 \mathrm{mg} / 100 \mathrm{gm}$ was recorded at the floating water level, with low nutrient treatment.

Table 1. The effect of water level and nutrients on survival (S), height (H) and total biomass (TB) of Cyperus laevigatus and Cyperus articulatus.

\begin{tabular}{|c|c|c|c|c|c|c|c|}
\hline \multicolumn{2}{|c|}{ Treatment } & \multicolumn{3}{|c|}{ Cyperus laevigatus } & \multicolumn{3}{|c|}{ Cyperus articulatus } \\
\hline Nutrient & Water level & $\begin{array}{l}\mathrm{S} \\
(\%)\end{array}$ & $\begin{array}{l}\mathrm{H} \\
(\mathrm{cm})\end{array}$ & $\begin{array}{l}\text { TB } \\
(\mathrm{g})\end{array}$ & $\begin{array}{l}\mathrm{S} \\
(\%)\end{array}$ & $\begin{array}{l}\mathrm{H} \\
(\mathrm{cm})\end{array}$ & $\begin{array}{l}\text { TB } \\
(\mathrm{g})\end{array}$ \\
\hline \multicolumn{8}{|l|}{ High } \\
\hline & above soil surface & 20 & 5.5 & 0.15 & 80 & 26.02 & 1.3 \\
\hline & with soil surface & 100 & 21.65 & 0.57 & 100 & 44.02 & 2.83 \\
\hline & below soil surface & 80 & 20.16 & 0.65 & 80 & 45.37 & 3.49 \\
\hline \multicolumn{8}{|l|}{ Low } \\
\hline & above soil surface & 90 & 13.5 & 0.43 & 70 & 28.03 & 1.21 \\
\hline & with soil surface & 90 & 21.4 & 1.36 & 70 & 41.03 & 2.27 \\
\hline & below soil surface & 95 & 15.6 & 0.82 & 80 & 26.6 & 2.52 \\
\hline
\end{tabular}

Effect of water level and nutrients on chemical composition of $C$. articulatus

In low nutrient treatment, the values of $\mathrm{Na}^{+}, \mathrm{K}^{+}$, total-P and total-N concentration in above-ground and below-ground parts of $C$. articulatus were decreased by decreasing water level Fig. 2.

The highest value $14.5 \mathrm{ppm}$ of $\mathrm{Na}^{+}$ concentration was found in immersed soil and lowest value $9.0 \mathrm{ppm}$ in low nutrient level in above-ground parts of $C$. articulatus.

The highest value of $\mathrm{K}^{+}$concentration (16.25 ppm) was found in the above-grounds parts of $C$. articulatus growing in immersed soil and the lowest value in floating soil in high nutrient level.

The total-P increased with increasing water level, the highest value $(0.117 \mathrm{mg} / 100 \mathrm{gm})$ was attained in the underground parts. The total-N concentration of both above-ground and belowground parts decreased with decreasing water level. The highest value $0.119 \mathrm{mg} / 100 \mathrm{gm}$ was found in moist soil and the lowest value 0.046 $\mathrm{mg} / 100 \mathrm{gm}$ in immersed soil in high nutrient level in above-ground parts of $C$. articulatus.

\section{Discussion}

The experiment conducted on $C$. laevigatus and 
C. articulatus shows that the total biomass of $C$. laevigatus decreased by the increase of water level in high nutrient medium. The highest values of plant height and survival were recorded where the water level was at soil surface. In low nutrient treatment survival of (C. laevigatus) showed increased values with the decreasing of water level. The highest value of total biomass and plant height were recorded where the water level was at soil surface. Kercher and Zedler [17,18] assessed the growth parameters of some wetland plant taxa under different water levels and Nutrient addition concentrations and they found that, the biomass, height and productivity of plants negatively correlated with the water level. This may be related to root air space.
For $C$. articulatus in the high nutrient treatment the total biomass increased by decreasing of water level. The highest value of (\%) survival and plant height were recorded where water level was at soil surface. In low nutrient treatment survival increased with the decrease of water level. The highest value of total biomass and height of $C$. articulatus are recorded where water level was at soil surface. Goslee, et al. [19] found that increasing of soil water level may cause reduction of dissolved oxygen in soil hence reduce plant growth. In low nutrient treatment the value of survival of $C$. articulatus increased by decreasing water level while the height and total biomass decreased by decreasing water level.

Table 2. Analysis of variance of the effect of nutrient and water levels on plant height, desity and biomass of Cyperus laevigatus and and Cyperus articulatus. Mean squares (MS) and F values are given.

\begin{tabular}{|c|c|c|c|c|c|c|}
\hline \multirow[b]{2}{*}{ Source of variation } & \multicolumn{3}{|c|}{ Cyperus laevigatus } & \multicolumn{3}{|c|}{ Cyperus articulatus } \\
\hline & df & $\mathrm{MS}$ & $\mathrm{F}$ & $\mathrm{df}$ & MS & $\mathrm{F}$ \\
\hline \multicolumn{7}{|l|}{ Plant height } \\
\hline Nutrient & 1 & 20.83 & $0.57 \mathrm{~ns}$ & 1 & 163.3 & $1.29 \mathrm{~ns}$ \\
\hline Water depth & 2 & 516.1 & $14.17 * * *$ & 2 & 572.1 & $4.53^{*}$ \\
\hline Nutrient \& Water depth & 2 & 352.9 & $9.69 * * *$ & 2 & 233.7 & $1.85 \mathrm{~ns}$ \\
\hline Error & 24 & 36.43 & & 24 & 126.2 & \\
\hline \multicolumn{7}{|l|}{ Plant density } \\
\hline Nutrient & 1 & 136.5 & $6.44 * *$ & 1 & 0.03 & $0.06 \mathrm{~ns}$ \\
\hline Water depth & 2 & 194.5 & $9.18 * * *$ & 2 & 0.63 & $1.12 \mathrm{~ns}$ \\
\hline Nutrient \& Water depth & 2 & 2.53 & $0.12 \mathrm{~ns}$ & 2 & 0.03 & $0.06 \mathrm{~ns}$ \\
\hline Error & 24 & 21.2 & & 24 & 0.57 & \\
\hline \multicolumn{7}{|l|}{ Biomass } \\
\hline Nutrient & 1 & 4.72 & $15.79 * * *$ & 1 & 9.98 & $5.47 * *$ \\
\hline Water depth & 2 & 2.98 & $9.97 * * *$ & 2 & 10.96 & $6.01 * *$ \\
\hline Nutrient \& Water depth & 2 & 0.31 & $1.02 \mathrm{~ns}$ & 2 & 3.18 & $1.74 \mathrm{~ns}$ \\
\hline Error & 24 & 0.3 & & 24 & 1.82 & \\
\hline
\end{tabular}

$* \mathrm{P}<0.05, * * \mathrm{P}<0.01, * * * \mathrm{P}<0.001, \mathrm{~ns}=$ not significant.

For C. laevigatus grown in high nutrient treatment, the values of $\mathrm{Na}^{+}$concentration increased in both below-ground and aboveground parts. In high nutrient treatment the values of $\mathrm{K}^{+}$concentration increased by increasing water level. In high nutrient treatment the highest values of total-P concentration recorded at water level with soil surface in both below-ground and above-ground parts. In low nutrient treatment the values of total- $\mathrm{N}$ concentration decreased by increasing water level in above-ground parts whereas in the belowground the highest value of total-N was recorded. Brinson and Malvarez [20] reported that the plant productivity was affected negatively with the increasing of water level. In high nutrient treatment the values of $\mathrm{Na}^{+}$concentration in both below-ground and above-ground of mixed culture were increased by increasing of water level. In high nutrient treatment the highest value of $\mathrm{K}^{+}$ concentration in both below-ground and aboveground was recorded at water level floating. For C. articulatus growing in low nutrient treatment the values of $\mathrm{Na}+, \mathrm{K}+$, total-P and total-N concentration decreased by increasing water level in below-ground according to Brinson and Malvarez [20]. In low nutrient treatment the values of total-P concentration decreased by increasing water level in above-ground. 


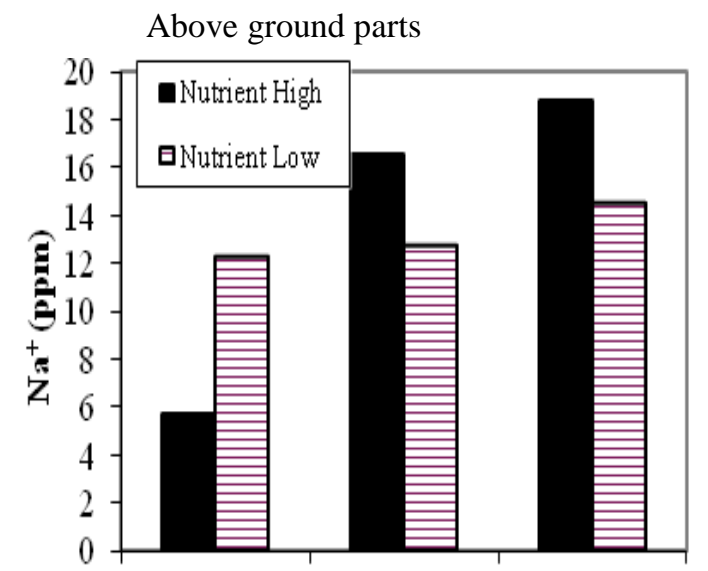

Below-ground parts
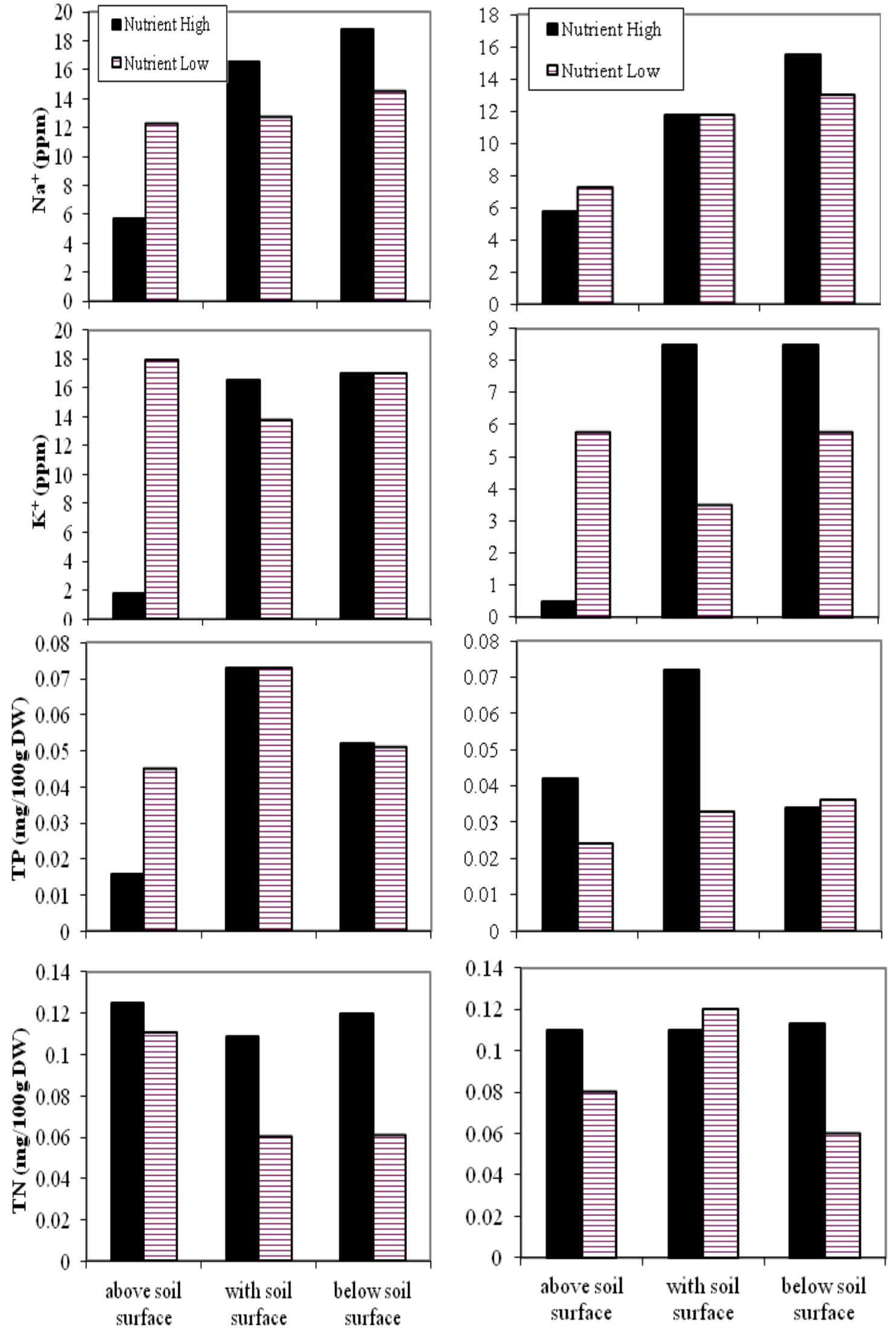

Fig. 1 The effect of water level and nutrients on the chemical composition of Cyperus laevigatus. 


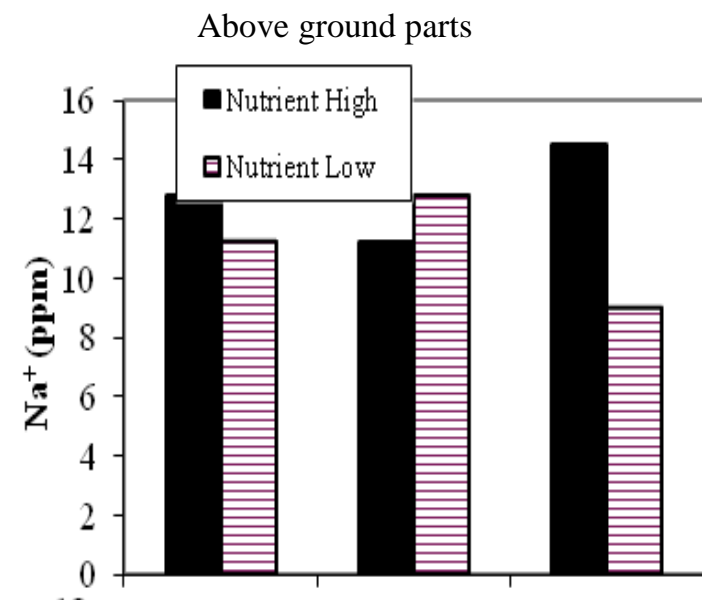

Below-ground parts
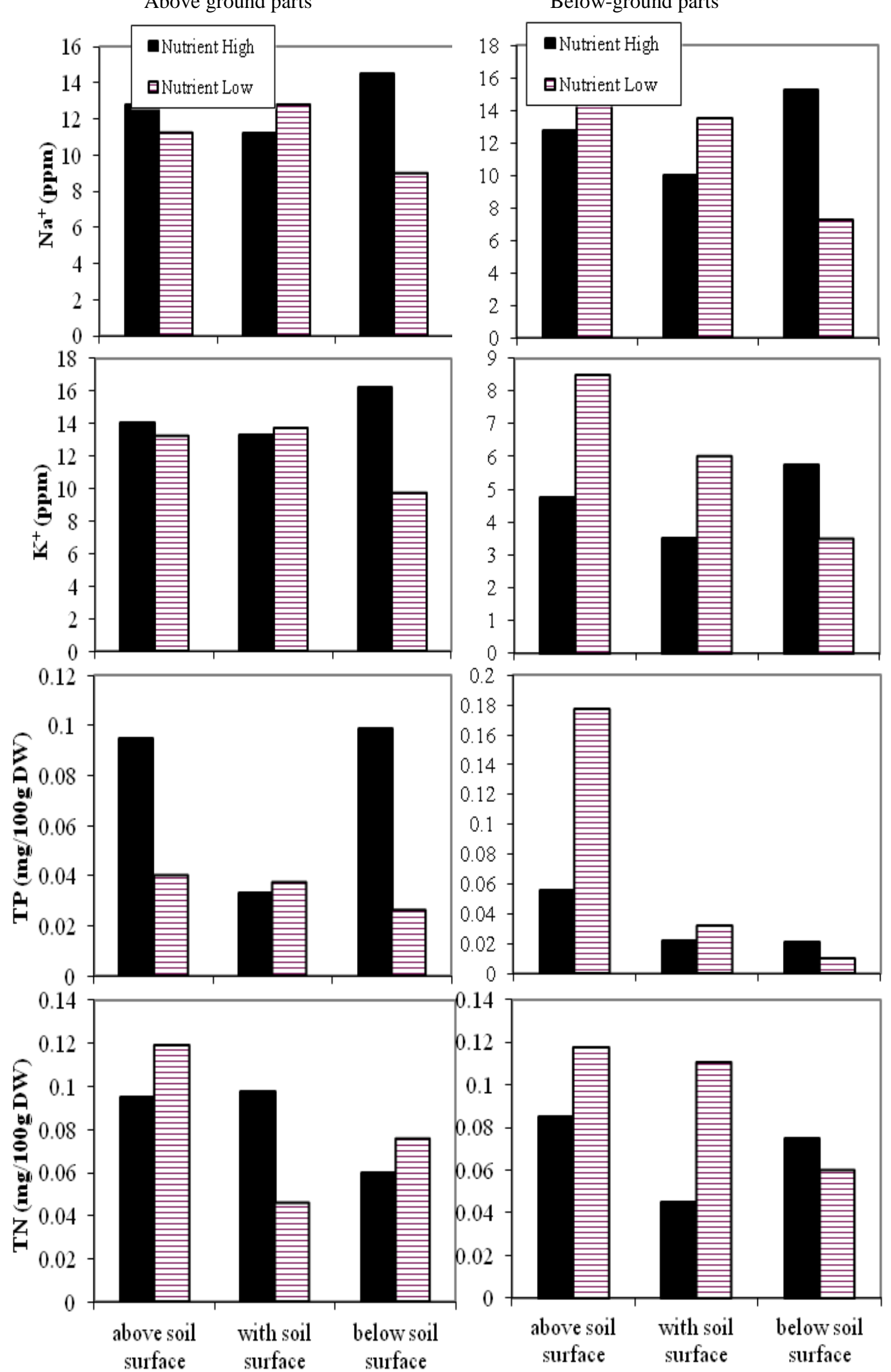

Fig. 2 The effect of water level and nutrients on the chemical composition of Cyperus articulatus. 
In high nutrient treatment of mixed culture the value of $\mathrm{Na}+$ concentration increased by increasing water level. The highest values of $\mathrm{K}+$, total-P and total-N concentration were recorded at water level floating in below-ground according to Carr and Chambers [21]. In low nutrient treatment of mixed culture the value of $\mathrm{K}+$ concentration decreased by increasing water level. In high nutrient treatment of mixed culture, the highest values of $\mathrm{K}+$ and total-P concentration in above-ground recorded at water level floating, while the highest value of total-N concentration in above-ground was recorded at water level moist. Kercher and Zedler [18] reported that the nutrient concentration and soil water level affect negatively or positively the growth parameters and the productivity of the wetland plants.

\section{References}

[1] M.S. Abdel-Razik, M.A. Ayyad, S.Z. Heneidy, Preference of grazing mammals for forage species and their nutritive value in a Mediterranean desert ecosystem (Egypt). Journal of Arid Environments 15 (1988) 297-305

[2] S.A. Ismail, Bibliography of Forage Halophytes and Trees for Salt-affected Land: Their use, culture and physiology. Karachi, Department of Botany, Univ. Karachi (1990) p 258

[3] N.I. Ashour, M.S. Serag, A.K. Abd El-Haleem, B.B. Mekki, Forage production from three grass species under saline irrigation in Egypt. Journal of Arid Environments 37 (1997) 299-307

[4] E.F. El-Halawany, I.A. Mashaly, A.M. AbdelGawad, On the ecology and fodder potentialities of some non conventional forage crops in the Nile Delta, Egypt. Journal of Environmental Sciences 35 (2008) 143-174

[5] B. Ladeiro, Saline Agriculture in the $21^{\text {st }}$ Century: Using Salt Contaminated Resources to Cope Food Requirements. Journal of Botany 1 (2012) 1-7

[6] H.C. Norman, D.G. Masters, E.G. BarrettLennard, Halophytes as forages in saline landscapes: Interactions between plant genotype and environment change their feeding value to ruminants. Environmental and Experimental Botany 92 (2013) 96-109

[7] A.A. Khedr, Aquatic macrophytes distribution in Lake Manzala, Egypt. International J. of Salt Lake Research 5 (1997) 221-239
[8] A.A. Khedr, Floristic composition and phytogeography in a Mediterranean deltaic lake (Lake Burollos), Egypt. Ecologia Mediterranea, 25 (1999) 1-11

[9] M. Abdullah, R.H. Qureshi, N. Ahmad, Responses of Leptochloa fusca to various types of substrate salinities. In: Prospects for Biosaline Research [Ahmad, R. and San Pietro, A. (eds.)], US-Pakistan Biosaline Research Workshop, Department of Botany, University of Karachi, Karachi, Pakistan (1986) 115-123

[10] I.A. Mashaly, Comparative ecological studies on two halophytes: Juncus subulatus and Diplachne fusca, Deltaic Mediterranean Coast, Egypt. Journal of Environmental Sciences 5 (1993) 279295

[11] M.A. Zahran, A.J. Willis, The Vegetation of Egypt. Chapman and Hall. Publ., London (1992) P440

[12] S.E. Allen, H. M. Grimshaw, J. A. Parkinson, C. Quarmby, J.D. Roberts, Methods in Plant Ecology. $2^{\text {nd }}$ edition (Ed. by P. D. Moore, S.B. Chapman). Black Well Scientific Publications Oxford (1986) 411- 466.

[13] M.K. John, Colorimetric determination of phosphorus in soil and plant materials with ascorbic acid. Soil Science 109 (1970) 214-220

[14] APHA-American Public Health Association Standard Methods for the Examination of Water, Wastewater. 18th Ed. Washington (1992)

[15] L. Boulos, Flora of Egypt. Checklist. Al Hadara Publishing, Cairo, Egypt (1995) p 286

[16] D.G. Kleibaum, L.L. Kupper, K.E. Muller, Oneway analysis of variance. In: Multivariate Methods, pp 341-386. Boston: PWS-Kent Publishing Company, (1998) p 718

[17] S. Kercher, J.B. Zedler, Flood tolerance in wetland and angiosperms: a comparison of invasive and noninvasive species. Aquatic Botany 80 (2004) 89-102

[18] S. Kercher, J.B. Zedler, Causes and consequences of invasive plants in wetlands: Opportunities, opportunists, and outcomes. Plant Sciences 23 (2004) 431-452

[19] S.C. Goslee, R.P. Brooks, C.A. Cole, Plants as indicators of wetland water source. Plant Ecology 131 (1997) 199-206

[20] M.M. Brinson, A.I. Malvarez, Temperate freshwater wetlands: types, status, and threats. Environmental Conservation 29 (2002) 115-133

[21] G.M. Carr, P.A. Chambers, Macrophyte growth and sediment phosphorus and nitrogen in a Canadian prairie river. Freshwater Biology Journal 39 (1998) 525-536 
الملخص العربي

دراسة تأثير اختلاف عمق المياه وإضافة المغذيات على النمو والتركيب الكيميائي لنوعين من نباتات الفصيلة السعدية فى دلتا التير النيل

$$
\text { قبد النبات ، كلية العلوم ، ممدوح سراجة دمياطى ربيع ، عافية دومة }
$$

تم دراسة تأثير مستويات مختلفة من الماء الأرضي فى ظروف غذائية مختلفة على نوعين من نباتات

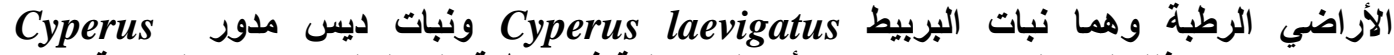
articulatus

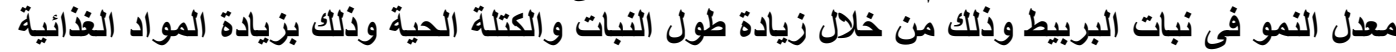

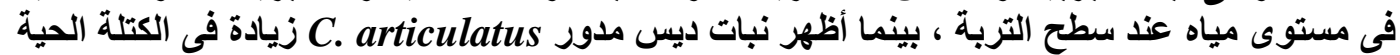

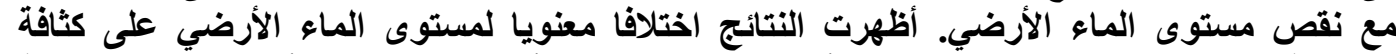

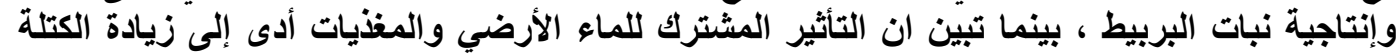

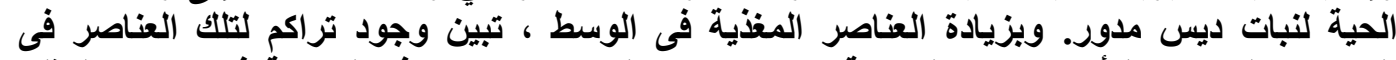

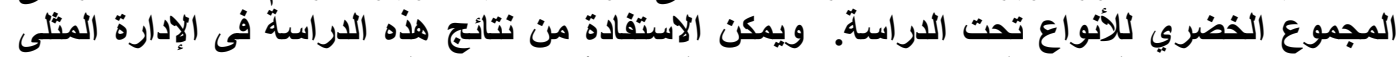

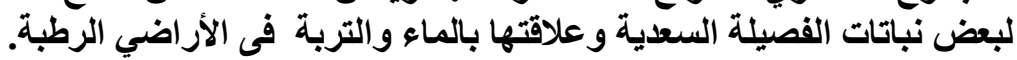

